EXTENDED REPORT

\title{
Genetic risk of knee osteoarthritis: a sibling study
}

\author{
R L Neame, K Muir, S Doherty, M Doherty
}

Ann Rheum Dis 2004;63:1022-1027. doi: 10.1136/ard.2003.014498

See end of article for authors' affiliations

a thors affilitions,

Correspondence to: Dr R Neame, Academic Rheumatology, Clinical Sciences Building, City Hospital, Nottingham, NG5 IPB, UK; Micháel. Doherty@nottingham. ac.uk

Accepted

19 December 2003

\begin{abstract}
Objectives: To determine whether there is a genetic contribution to knee osteoarthritis (OA) as defined by structural change on plain radiographs.

Design: Sibling study. Comparison of knee OA prevalence in the community with knee OA prevalence among siblings of index cases with knee OA.

Subjects: 490 knee OA index cases listed for total knee replacement and 737 of their siblings aged $>40$ years, 1729 community subjects aged $>40$ years.

Main outcome measure: Odds ratio for radiographic knee $O A$ in siblings $v$ community participants.

Results: The age, sex, and knee pain adjusted odds ratios in siblings were $2.9195 \%$ confidence interval 2.3 to 3.7) for tibiofemoral OA and 1.7 (1.4 to 2.2) for patellofemoral OA. This difference remained after adjustment for important environmental risk factors. The heritability estimate for knee OA was 0.62 .

Conclusions: Siblings are at increased risk of knee OA in comparison with the general population. This is likely to be due to genetic factors.
\end{abstract}

$\mathrm{O}$ steoarthritis (OA) is a common age associated multifactorial condition. ${ }^{1}$ The knee is the most clinically significant site affected, with an estimated $10 \%$ of the population aged $>55$ experiencing pain and severe disability. ${ }^{2}$ Few studies have examined in detail the genetic contribution to knee OA. A classic twin study undertaken in the UK has estimated the heritability of knee OA-that is, the proportion of the variance in occurrence of knee OA that may be explained by genetic factors, to be $39 \% .^{3}$ Further analyses have shown that the association between knee OA and high body mass index, which has a heritable component, is unlikely to be mediated by shared genetic factors. ${ }^{4}$ However, this is the only twin study of knee OA and the study included only women. Another strategy was to examine the risks for total knee replacement (TKR) and total hip replacement in siblings of subjects who had undergone these procedures. The relative risks of joint replacement in this UK study were 4.8 at the knee and 1.9 at the hip. However, the confidence intervals (CIs) were wide, these data were not adjusted for important risk factors, and spouses were used as the control population. Two community studies in North America and the Netherlands have investigated familial aggregation and segregation of OA but have found no evidence for a genetic contribution at the knee. ${ }^{67}$ However, the first of these studies was limited by the absence of patellofemoral joint (PFJ) views and the young age of participants, and the second study may have included too few subjects to show an effect. We therefore undertook a sibling study to better estimate the genetic contribution to symptomatic and clinically significant knee OA. Importantly, our design included assessment of all three knee compartments, community subjects as controls, and adjustment for recognised constitutional and environmental risk factors for knee OA.

\section{METHODS}

\section{Ethical approval}

Approval was obtained from the North Nottinghamshire Research Ethics Committee and the Nottingham City Hospital Research Ethics Committee.

\section{Ascertainment of index cases of knee OA}

Index cases were 2857 white patients who had undergone or were awaiting TKR for OA at three Nottinghamshire orthopaedic centres between 1997 and 2000. These people were ascertained from the Trent regional arthroplasty list, an electronic database. All patients undergoing this procedure within the NHS (National Health Service) in the Trent region should be "captured" on this database. Those who had been, or would be, $<40$ years old at the time of operation were excluded. Those with a self reported diagnosis of inflammatory arthritis, trauma, or joint sepsis were excluded at this stage. Diagnosis was validated by reviewing the preoperative radiographs.

All local index subjects were sent a questionnaire asking for the contact details of all of their siblings, regardless of whether they were thought to have arthritis. Non-responders were re-mailed after 4 weeks.

\section{Ascertainment of siblings}

Siblings were identified from the questionnaire responses of the index subjects; half-siblings and those aged $<40$ were excluded.

To reduce oversampling those with $\mathrm{OA}$, only eligible siblings living locally were asked to attend for metrologist interview and examination and to undergo knee radiographs. It was emphasised that all participants would be welcomed, regardless of whether or not they had arthritis. Those who did not reply were re-mailed after 4 weeks, and the ages of non-responders were obtained by telephone contact. Consent to examine any previous knee radiographs was sought from non-local siblings.

\section{Ascertainment of community participants}

Data and radiographs from Nottingham community based knee pain studies performed at our centre between 1995 and 1999 were used. Random samples aged $>40$ from general practice lists in Nottingham had been surveyed using postal questionnaires. ${ }^{89}$ Subjects were defined as having knee pain if they responded yes to "Have you ever had pain in or around the knee on most days for at least a month?" and "If so, have you experienced any pain during the last year?" In nested case-control studies those with current knee pain were

Abbreviations: $\mathrm{BMI}$, body mass index; $\mathrm{Cl}$, confidence interval; $\mathrm{OA}$, osteoarthritis; OR, odds ratio; PFJ, patellofemoral joint; PF OA, patellofemoral osteoarthritis; RR, risk ratio; TFJ, tibiofemoral joint; TF OA, tibiofemoral osteoarthritis; TKR, total knee replacement 
matched for age and sex with those without, and these groups were then asked to undergo knee radiographs. In a nested intervention study only those with knee pain underwent radiographs and clinical examination. Exclusion criteria included TKR (although those awaiting this procedure were included), terminal illness, and incapacity to give informed consent.

\section{Data collection: knee OA risk factors}

Postal questionnaires mailed to the community participants and to the siblings were used to collect data on age, sex, presence or absence of knee pain, knee injuries or operations, and smoking history. Metrologists measured body mass index (BMI) in $\mathrm{kg} / \mathrm{m}^{2}$ and examined for Heberden's or Bouchard's nodes. Reproducibility for the assessment of nodes was assessed by three metrologists re-examining a group of 10 patients, showing a spectrum of hand changes, in random order on the same day.

\section{Radiographic technique: siblings}

The majority (556) of sibling radiographs were performed as for the community sample.

An additional currently available 92 sibling radiographs were paired schuss ${ }^{10}$ and skyline views. The remaining nonlocal siblings had non-standardised radiographs, as did local siblings who had undergone knee radiographs in the preceding 6 months.

\section{Radiographic technique: community sample}

All radiographs were taken under the same standardised conditions, and were weightbearing, fully extended, anteroposterior views $(55 \mathrm{kV}, 8 \mathrm{~mA} / \mathrm{s}$, full scale deflection $100 \mathrm{~cm}$, and skyline $30^{\circ}$ flexion views $(60 \mathrm{kV}, 10 \mathrm{~mA} / \mathrm{s}$, full scale deflection $100 \mathrm{~cm}$ ) after the method of Laurin et $a l^{11}$ using standard Fuji film.

\section{Radiographic assessment: grading}

A single observer (RLN) read all the radiographs. Community radiographs and the 556 paired sibling radiographs that had been performed in the same way were mixed and read "blind". The remaining sibling radiographs could not be "blinded", and the most recent radiographs for both knees were assessed. If a TKR was evident the film just before surgery was selected.

Radiographs of the tibiofemoral joint (TFJ) and the PFJ (lateral views) were assigned Kellgren and Lawrence grades. ${ }^{12}$ Individual features of OA at both the TFJ and the PFJ (skyline views) were assessed using an adaptation of a validated line drawing atlas. ${ }^{13}$ Joint space narrowing in all compartments was graded -1 to 5 . Osteophyte was graded 0 to 5 at all sites (medial and lateral femoral trochlear, medial and lateral patella, medial and lateral femoral condyle, and medial and lateral tibia).

\section{Radiographic assessment: reproducibility}

Reproducibility was examined half way through the study by re-reading 40 community radiographs 1 month after the first assessment. Radiographs were chosen by an independent researcher to represent a broad range of OA severity.

\section{Case definition}

OA was defined on the basis of structural change. The definitions of OA were:

- Definite tibiofemoral OA (TF OA)-that is, Kellgren and Lawrence grade $\geqslant 2$ at the TFJ

- Moderate-severe TF OA-that is, Kellgren and Lawrence grade 3-4 at the TFJ

- Definite patellofemoral OA (PF OA)-that is, for skyline radiographs: line atlas osteophyte score $\geqslant 2$ plus joint space narrowing score $\geqslant 2$; for lateral radiographs: Kellgren and Lawrence grade $\geqslant 2$
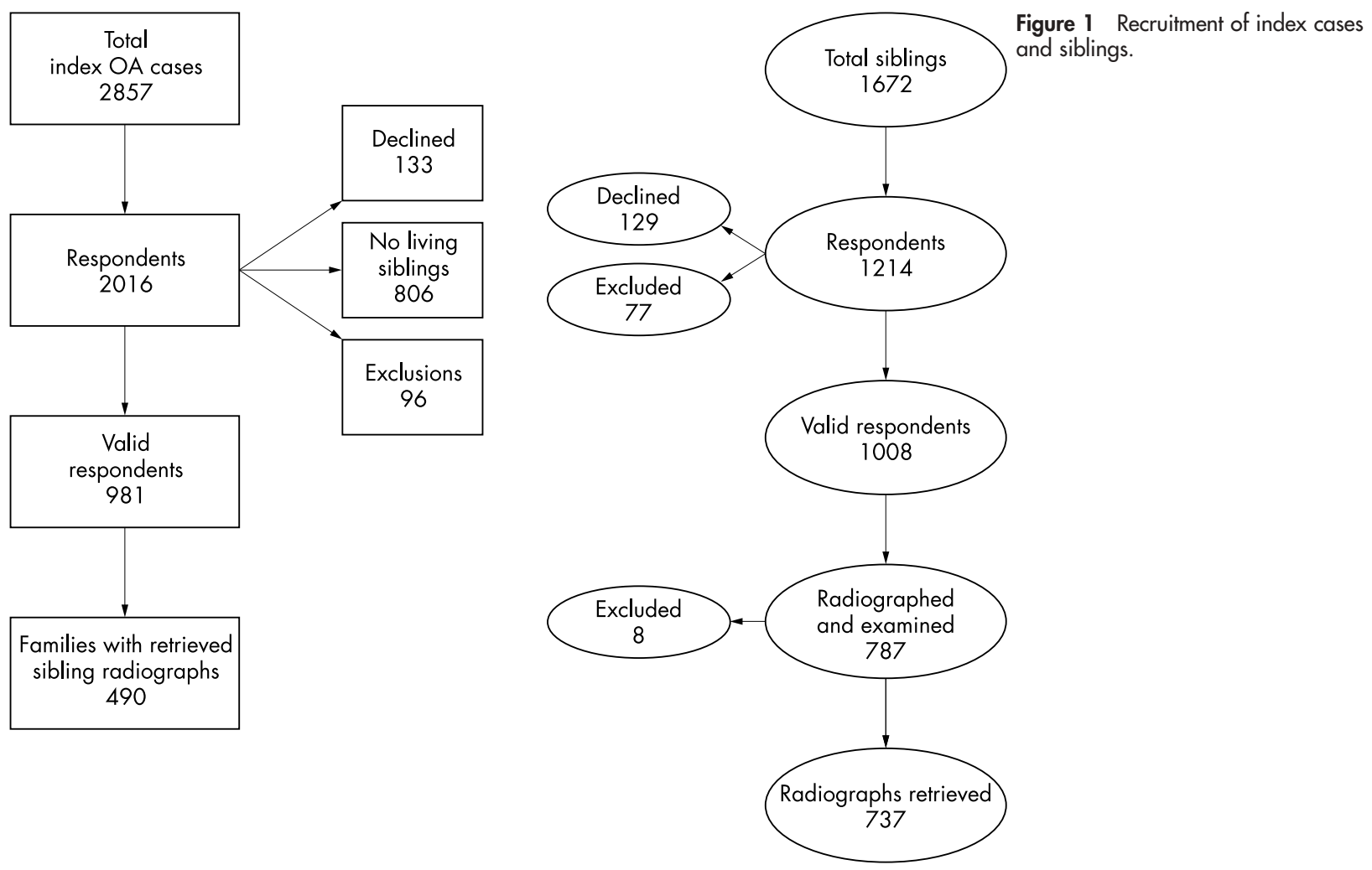
Table 1 Participant characteristics

\begin{tabular}{|c|c|c|c|c|c|c|c|c|c|c|}
\hline & \multicolumn{5}{|l|}{ Women } & \multicolumn{5}{|l|}{ Men } \\
\hline & No & Community & No & Siblings & $p$ & No & Community & No & Siblings & $\mathbf{p}$ \\
\hline Age (years), mean (SD) & $(n=1085)$ & $63.4(9.5)$ & $(n=423)$ & $68.1(8.6)$ & $<0.001$ & $(n=644)$ & $64.2(9.3)$ & $(n=314)$ & $66.7(8.1)$ & \\
\hline With knee pain (\%) & $(n=1085)$ & 58.2 & $(n=423)$ & 59.8 & 0.949 & $(n=644)$ & 57.3 & $(n=314)$ & 58.5 & 0.504 \\
\hline BMI $\left(\mathrm{kg} / \mathrm{m}^{2}\right)$, mean (SD) & $(n=1082)$ & $26.8(4.6)$ & $(n=416)$ & $27.6(5.3)$ & 0.003 & $(n=641)$ & $26.9(3.8)$ & $(n=308)$ & $26.9(4.0)$ & \\
\hline Smoking: & $(n=1061)$ & & $(n=423)$ & & & $(n=632)$ & & $(n=314)$ & & \\
\hline Never smoked (\%) & & 54.2 & & 52.7 & 0.607 & & 29.3 & & 28.0 & 0.704 \\
\hline Ex-smokers (\%) & & 33.0 & & 15.4 & $<0.001$ & & 54.9 & & 14.6 & $<0.001$ \\
\hline Current smokers (\%) & & 12.8 & & 31.9 & $<0.001$ & & 15.8 & & 57.3 & $<0.001$ \\
\hline With nodes (\%) & $(n=556)$ & 42.1 & $(n=423)$ & 69.5 & $<0.001$ & $(n=297)$ & 25.6 & $(n=308)$ & 43.0 & $<0.001$ \\
\hline Meniscectomy (\%) & $(n=882)$ & 0.1 & $(n=423)$ & 1.9 & $<0.001$ & $(n=512)$ & 4.3 & $(n=314)$ & 8.3 & 0.018 \\
\hline
\end{tabular}

- Moderate-severe PF OA-that is, for skyline radiographs: line atlas osteophyte score $\geqslant 3$ plus joint space narrowing score $\geqslant 3$; for lateral radiographs: Kellgren and Lawrence grade $3-4$.
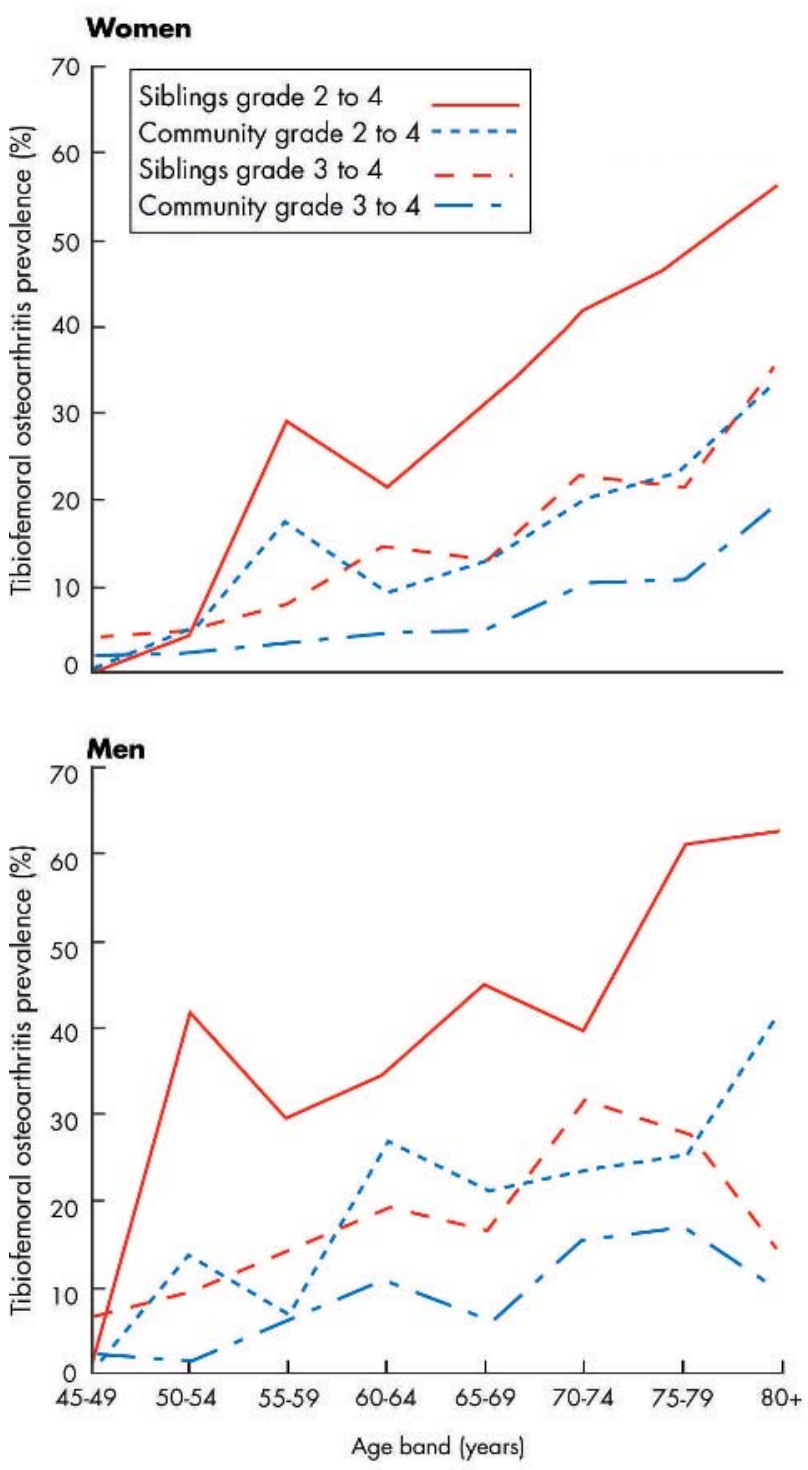

Figure 2 Tibiofemoral osteoarthritis prevalence in siblings and in the community.

\section{Data analysis}

The TFJ radiograph with the highest Kellgren and Lawrence grade and the right knee PFJ film were analysed for each subject. Reproducibility for OA grading was assessed by the $\kappa$ statistic ${ }^{14}$ using STATA for windows. ${ }^{15}$ Direct standardisation of OA prevalence was by age, sex, and knee pain status using data from a Nottingham survey. ${ }^{8}$ Odds ratios (ORs) from logistic regression using SPSS were used to examine risk factors for OA. $^{16}$ Poisson regression analysis was with STATA. ${ }^{15}$ Heritability was calculated by comparing the liability to OA among siblings with that among the community ${ }^{17}$ using age standardised prevalence estimates. ${ }^{18}$ The assumptions were that liability to OA was distributed normally in both groups, and the variances were equal.

\section{RESULTS}

Response rate: index cases

Questionnaires were mailed to 2857 index cases. After the second mailing 2016 replies were received, a response rate of $70.6 \%$ (fig 1). From these the following were excluded: 133 who did not want to participate, 806 with no living siblings, 32 who did not supply siblings' contact details, 7 with half-siblings, 30 who had died, and 27 with alternative diagnoses. The final pool of index cases consisted of 981 valid respondents, 490 of whom had valid siblings who participated in the study. Of the later group 460 preoperative radiographs of the index cases confirmed OA, and 30 could not be retrieved but their siblings were included.

\section{Response rate: siblings}

Invitations were mailed to 1672 siblings, including 348 who were not local. These 1672 people were derived from the 981 index cases. 1214 replies were received, a response rate of $72.6 \%$ (fig 1). From these the following were excluded: 129 declined participation, 12 were not siblings, 19 had died, 7 were too unwell, 5 were aged $<40$, and 34 had index cases who did not have primary OA. The remaining 1008 valid respondents were invited to undergo knee radiographs. Of these, $787(78.1 \%)$ were subsequently radiographed, 8 were excluded owing to inflammatory arthritis, and radiographs of 737 siblings were retrieved.

\section{Response rate: community sample}

The overall response rate to the two postal questionnaires was $70.1 \%$ after the second mailing. For participants of the nested case-control studies asked to undergo radiographs, uptake was $92 \%$ among participants with knee pain and $77 \%$ among participants without knee pain.

\section{Study population characteristics}

The 490 index cases comprised 276 women (56.3\%, mean age 70.5 years) and 214 men (43.7\%, mean age 68.7 years). All 

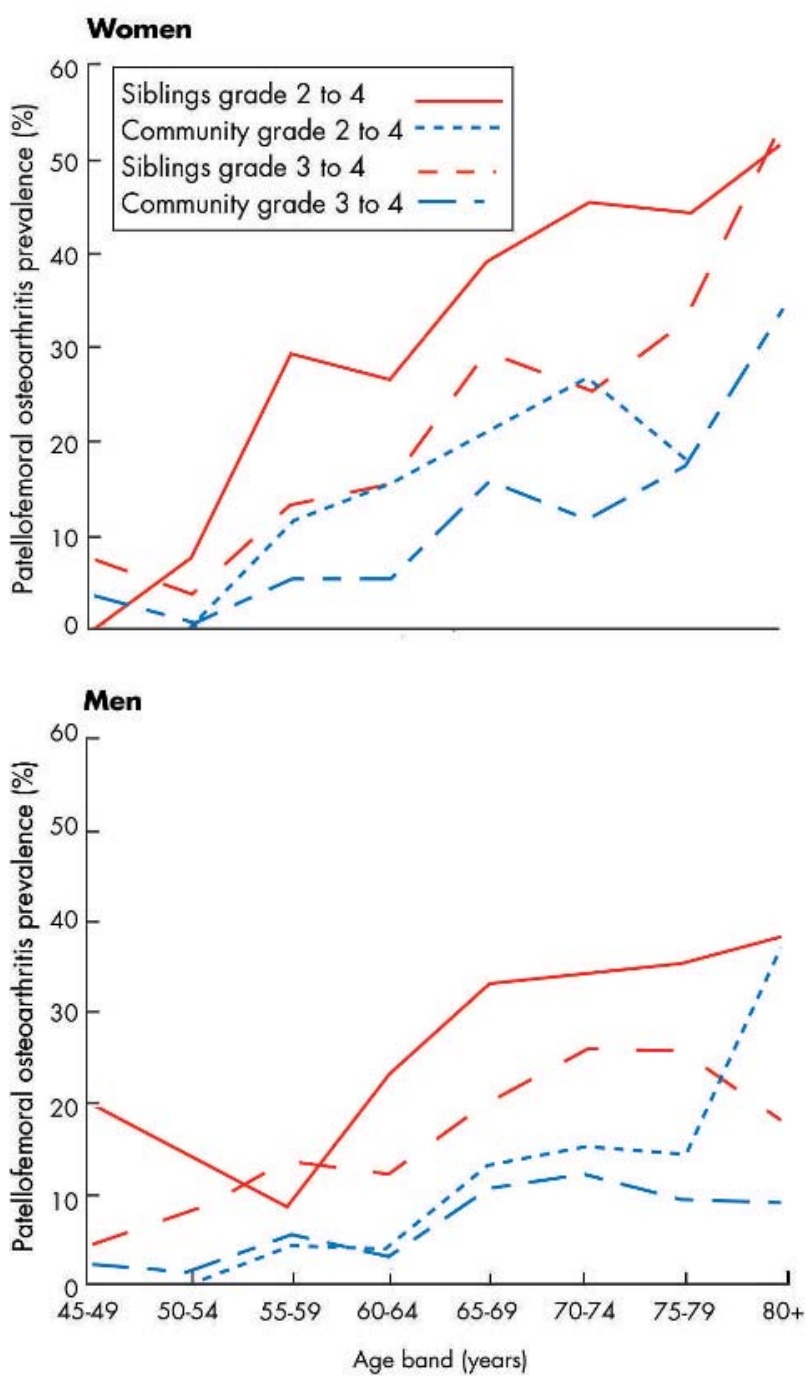

Figure 3 Patellofemoral osteoarthritis prevalence in siblings and in the community.

the siblings were white, as were $99 \%$ of the community group. The 737 siblings were older than the 1729 community participants (table 1) and comprised a higher proportion of men $(42.6 \% \vee 37.2 \%, p=0.012)$. Knee pain was common among both groups. The mean BMI of male siblings did not significantly differ from that of male community participants. Female siblings were heavier than female community participants, although this difference was small (mean difference $0.8 \mathrm{~kg} / \mathrm{m}^{2}, 95 \%$ CI 0.3 to $1.4 \mathrm{~kg} / \mathrm{m}^{2}$ ). Similar proportions of community participants and siblings had never smoked, but a higher proportion of siblings were current smokers. The presence of nodes and history of meniscectomy were more common among siblings.

The age-sex distribution of 235 (53\%) of the non-responder siblings was known, and this group contained proportionally more men $(48.1 \%)$. Non-responders were similar in age to participants (women: mean 68.6 years; men: mean 64.9 years).

\section{Reproducibilty of OA assessments}

Reproducibility for OA assessments was good. The $\kappa$ coefficient was 0.84 for Kellgren and Lawrence grades, and ranged from 0.69 to 0.90 for line atlas features.
Reproducibility for assessment of nodes

Intraobserver reproducibility was good, with $\kappa$ coefficient $\geqslant 0.75$ at all sites; interobserver reproducibility was also good, with $\kappa$ coefficient $\geqslant 0.6$ at all sites.

\section{Knee OA prevalence}

Knee OA was strongly age associated (figs 2 and 3). A $\chi^{2}$ test for trend for the association between OA and age was highly significant for the siblings and the community sample $(\mathrm{p}<0.0001$ for both samples $)$. TF OA was more common in men, whereas PF OA was more common among women. The prevalence of knee OA was higher in siblings than among the community for all definitions, excepting moderate-severe PF $\mathrm{OA}$ in men, for which prevalences were similar.

The age, sex, and knee pain standardised prevalence estimates confirm the excess of knee OA among siblings (table 2).

\section{Effect of other key risk factors}

Adjusting for important knee OA risk factors did not alter the finding of an increased knee OA risk in siblings (table 3). For self reported knee injury and operations, only meniscectomy was associated with $\mathrm{OA}$ and hence was used in these calculations.

\section{Sensitivity analysis and heritability estimate}

Selection of one sibling from each family for analysis did not alter the increased chance of knee OA among siblings, with age, sex, and knee pain adjusted OR $=2.8$ (95\% CI 2.0 to 3.9).

Exclusion of the 181 siblings with "unblinded" radiographs had no influence on the main finding, with adjusted OR 2.3 (95\% CI 1.9 to 3.0). The excess of OA among siblings was maintained when the 23 siblings who had undergone TKR were omitted from analysis, giving adjusted OR 2.4 (95\% CI 1.9 to 3.0$)$.

Risk ratios (RRs) were calculated by Poisson regression using age as a surrogate for "genetic" exposure duration. The adjusted RRs were similar to the ORs with $\mathrm{RR}=1.6(95 \% \mathrm{CI}$ 1.4 to 2.0 ).

The heritability $\left(\mathrm{h}^{2}\right)$ of knee OA was estimated at 0.62 overall (95\% CI 0.49 to 0.75$)$.

\section{DISCUSSION}

This study shows that siblings had double the risk of knee OA compared with community people. This is despite the fact that the community group was not a true random sample, as people with knee pain were overrepresented, and therefore the prevalence of $\mathrm{OA}$ among this group is probably an overestimate. The heritability of knee OA, with $62 \%$ of disease variance likely to be genetically determined, is greater than previous estimates. ${ }^{35}$ Interestingly, we found that heritability was higher in men (0.78) than in women (0.49). This may explain why our overall estimate is higher than that reported in a previous twin study that was restricted to women (heritability 0.39 ). ${ }^{3}$ Of further interest is a study of similar design to ours that reported an increased risk of hip $\mathrm{OA}$ in male siblings compared with female siblings ${ }^{19}$ The heritability (0.31) reported in the Oxford study was based on the phenotype of either hip or knee replacement rather than the more stringent criterion of radiographic knee OA as in our study. ${ }^{5}$ It is likely that this difference in phenotype is in part responsible for the difference in heritability estimates. Furthermore, spouses acted as controls in the Oxford study. It is recognised that assortative mating may occur, leading to similarities for disease between spouses, and these may have reduced the heritability estimates in that study. ${ }^{20}$

The significantly increased risk of OA amongst siblings remained after adjustment for other key risk factors known 
Table 2 Age, sex, and knee pain standardised prevalence estimates

\begin{tabular}{|c|c|c|c|c|c|c|}
\hline \multirow[b]{2}{*}{ Definition } & \multicolumn{2}{|l|}{ Women } & \multicolumn{2}{|l|}{ Men } & \multicolumn{2}{|l|}{ Both sexes } \\
\hline & $\begin{array}{l}\text { Community } \\
\text { ( } n=1085)\end{array}$ & $\begin{array}{l}\text { Siblings } \\
(\mathrm{n}=423)\end{array}$ & $\begin{array}{l}\text { Community } \\
(n=644)\end{array}$ & $\begin{array}{l}\text { Siblings } \\
(n=314)\end{array}$ & $\begin{array}{l}\text { Community } \\
\text { ( } n=1729 \text { ) }\end{array}$ & $\begin{array}{l}\text { Siblings } \\
(n=737)\end{array}$ \\
\hline TF OA & $\begin{array}{l}6.4 \\
(4.9 \text { to } 7.9)\end{array}$ & $\begin{array}{l}13.9 \\
(10.6 \text { to } 17.2)\end{array}$ & $\begin{array}{l}9.5 \\
(7.2 \text { to } 11.8)\end{array}$ & $\begin{array}{l}20.0 \\
(15.6 \text { to } 24.4)\end{array}$ & $\begin{array}{l}7.9 \\
(6.6 \text { to } 9.2)\end{array}$ & $\begin{array}{l}16.8 \\
(14.1 \text { to } 19.5)\end{array}$ \\
\hline Moderate-severe TF OA & $\begin{array}{l}3.0 \\
(2.0 \text { to } 4.0)\end{array}$ & $\begin{array}{l}5.7 \\
(3.5 \text { to } 7.9)\end{array}$ & $\begin{array}{l}3.6 \\
(2.2 \text { to } 5.0)\end{array}$ & $\begin{array}{l}9.3 \\
(6.1 \text { to } 12.5)\end{array}$ & $\begin{array}{l}3.3 \\
(2.5 \text { to } 4.1)\end{array}$ & $\begin{array}{l}7.4 \\
(5.5 \text { to } 9.3)\end{array}$ \\
\hline Bilateral TF OA & $\begin{array}{l}3.6 \\
(2.5 \text { to } 4.7)\end{array}$ & $\begin{array}{l}6.2 \\
(3.9 \text { to } 8.5)\end{array}$ & $\begin{array}{l}4.5 \\
(2.9 \text { to } 6.1)\end{array}$ & $\begin{array}{l}8.8 \\
(5.7 \text { to } 11.9)\end{array}$ & $\begin{array}{l}4.0 \\
(3.1 \text { to } 4.9)\end{array}$ & $\begin{array}{l}7.4 \\
(5.5 \text { to } 9.3)\end{array}$ \\
\hline PF OA & $\begin{array}{l}11.2 \\
(9.3 \text { to } 13.1)\end{array}$ & $\begin{array}{l}18.8 \\
(15.1 \text { to } 22.5)\end{array}$ & $\begin{array}{l}10.4 \\
(8.0 \text { to } 12.8)\end{array}$ & $\begin{array}{l}16.9 \\
(12.8 \text { to } 21.0)\end{array}$ & $\begin{array}{l}10.8 \\
(9.3 \text { to } 12.3)\end{array}$ & $\begin{array}{l}17.9 \\
(15.1 \text { to } 20.7)\end{array}$ \\
\hline Moderate-severe PF OA & $\begin{array}{l}5.3 \\
(4.0 \text { to } 6.6)\end{array}$ & $\begin{array}{l}8.8 \\
(6.1 \text { to } 11.5)\end{array}$ & $\begin{array}{l}4.3 \\
(2.7 \text { to } 5.9)\end{array}$ & $\begin{array}{l}3.5 \\
(1.5 \text { to } 5.5)\end{array}$ & $\begin{array}{l}4.8 \\
(3.8 \text { to } 5.8)\end{array}$ & $\begin{array}{l}6.3 \\
(4.6 \text { to } 8.0)\end{array}$ \\
\hline Bilateral PF OA & $\begin{array}{l}4.2 \\
(3.0 \text { to } 5.4)\end{array}$ & $\begin{array}{l}8.6 \\
(5.9 \text { to } 11.3)\end{array}$ & $\begin{array}{l}4.1 \\
(2.6 \text { to } 5.6)\end{array}$ & $\begin{array}{l}4.6 \\
(2.3 \text { to } 6.9)\end{array}$ & $\begin{array}{l}4.2 \\
\text { (3.3 to } 5.2)\end{array}$ & $\begin{array}{l}6.7 \\
(4.9 \text { to } 8.5)\end{array}$ \\
\hline OA any knee site & $\begin{array}{l}13.7 \\
(11.7 \text { to } 15.8)\end{array}$ & $\begin{array}{l}29.7 \\
(25.4 \text { to } 34.1)\end{array}$ & $\begin{array}{l}14.7 \\
(12.0 \text { to } 17.4)\end{array}$ & $\begin{array}{l}29.1 \\
(24.1 \text { to } 34.1)\end{array}$ & $\begin{array}{l}14.2 \\
(12.6 \text { to } 15.9)\end{array}$ & $\begin{array}{l}29.5 \\
(26.2 \text { to } 32.8)\end{array}$ \\
\hline
\end{tabular}

Results are shown as percentage $(95 \% \mathrm{Cls})$

TF OA, tibiofemoral OA; PF OA, patellofemoral OA.

\begin{tabular}{lccc}
\hline Table 3 & Odds ratios of OA in siblings & & \\
\hline Definition & Women & Men & Both sexes* \\
\hline TF OA & 2.0 & 3.0 & 2.5 \\
& $(1.4$ to 3.1$)$ & $(1.9$ to 5.0$)$ & $(1.8$ to 3.4$)$ \\
Moderate-severe TF OA & 2.4 & 2.6 & 2.5 \\
Bilateral TF OA & $(1.4$ to 4.1$)$ & $(1.4$ to 4.6$)$ & $(1.7$ to 3.7$)$ \\
PF OA & 1.8 & 2.1 & 2.0 \\
& $(1.1$ to 3.0$)$ & $(1.2$ to 3.8$)$ & $(1.3$ to 2.9$)$ \\
Moderate-severe PF OA & 1.7 & 2.0 & 1.9 \\
& $(1.2$ to 2.6$)$ & $(1.2$ to 3.5$)$ & $(1.4$ to 2.6$)$ \\
Bilateral PF OA & 1.7 & 1.6 & 1.6 \\
& $(1.0$ to 2.6$)$ & $(0.7$ to 3.5$)$ & 1.1 to 2.4$)$ \\
& 1.4 & 3.0 & $(1.2$ to 2.7$)$ \\
\hline TF OA, tibiofemoral OA; PF OA, patellofemoral OA. & $(1.4$ to 6.5) & \\
(95\% Cls), adjusted for age, knee pain, BMl, smoking, Heberden's or Bouchard's nodes, and meniscectomy; *also \\
adjusted for sex.
\end{tabular}

to influence knee OA: age, sex, BMI, smoking, presence of Heberden's or Bouchard's nodes, and meniscectomy. The genetic risk was present in both men and women across a broad age span. It has been suggested that risk factors for OA at the TFJ and PFJ may differ from one another, ${ }^{21}$ but sibling risk of OA at the TFJ was similar to that at the PFJ. Similarly, there were no real differences in genetic risk at both joints according to radiographic severity of OA. However, the smaller numbers of people with more severe disease may have precluded the detection of any such difference. Sensitivity analyses showed that the increased risk in siblings was robust as it was unaffected by inclusion of only one sibling from each family, exclusion of siblings with TKR, or by statistical methodology.

This observed genetic risk may be generalised to the wider community as efforts were made to ensure that representative samples were studied. Exclusion of young index cases, together with review of preoperative radiographs, ensured that people with premature forms of OA or alternative diagnoses were omitted. Recruitment was restricted to siblings who lived locally. The purpose of this was to reduce the chance of oversampling siblings with knee OA, as it is conceivable that those with knee symptoms and knee OA would be more likely to travel to take part in the study. In addition, emphasis was also placed on recruiting all local siblings whether or not they had a knee problem, with the aim of reducing the chances of people with knee OA being preferentially recruited. The response rates were good, reducing the potential for non-responder bias.
There are several caveats to this study. Firstly, we calculated heritability in order to enable comparison with other studies, but it should be interpreted with care as we were able to adjust only for age. Secondly, although an increased risk of OA was observed in siblings after adjustment for important risk factors, aspects of shared family environment such as sporting and leisure activities or diet, which were not assessed, may contribute to the observed apparent genetic risk. However, associations between OA and these factors are not well established, and would be unlikely to completely explain the increased prevalence of knee OA among siblings. A third caveat is that the twofold increased risk of knee OA relates to siblings of patients with severe disease (who needed TKR) and it is unknown whether the risk may be less marked in families with milder disease. Finally, this study included only white people and there is a need to investigate the role of genetics in OA among other ethnic groups.

This is the first large sibling study of knee OA and adds to the growing body of evidence that there is a genetic contribution to common forms of OA. Identification of the responsible genes will enhance our understanding of OA pathogenesis.

\section{ACKNOWLEDGEMENTS}

We are indebted to all the participants in these studies. We acknowledge the assistance of Alison Carr with statistical advice, and Margaret Ball, Sheila O'Reilly, Kim Thomas, Margaret Wheeler, and Elizabeth Williams with data retrieval. 
We are grateful to GlaxoSmithKline, USA for financial support (RLN) and the Arthritis Research Campaign for infrastructure support (ICAC grant D0541).

\section{Authors' affiliations}

R L Neame, S Doherty, M Doherty, Academic Rheumatology, Clinical Sciences Building, City Hospital, Nottingham, NG5 IPB, UK

K Muir, Epidemiology and Public Health, Queen's Medical Centre, Nottingham, NG7 2UH, UK

\section{REFERENCES}

1 Felson DT, Lawrence RC, Dieppe PA, Hirsch R, Helmick CG. Osteoarthritis: new insights. Part 1. The disease and its risk factors. Ann Intern Med 2000;133:635-6.

2 Peat G, McCarney R, Croft P. Knee pain and osteoarthritis in older adults: a review of the community burden and current use of primary health care. Ann Rheum Dis 2001;60:91-7.

3 Spector TD, Cicuttini F, Baker J, Loughlin J, Hart DJ. Genetic influences on osteoarthritis in women: a twin study. BMJ 1996;312:940-3.

4 Manek NJ, Hart D, Spector TD, MacGregor AJ. The association of body mass index and osteoarthritis of the knee joint. Arthritis Rheum 2003;48:1024-9.

5 Chitnavis J, Sinsheimer JS, Clipsham K, Loughlin J, Sykes B, Burge PD, et al. Genetic influences in end-stage osteoarthritis. Sibling risks of hip and knee replacement for idiopathic osteoarthritis. J Bone Joint Surg $\mathrm{Br}$ 1997; 79:660-4

6 Hirsch R, Lethbridge-Cejku M, Hanson R, Scott WW, Reichle R, Plato CC, et al. Familial aggregation of osteoarthritis. Arthritis Rheum 1998:41:1227-32.

7 Bijkerk C, Houwing-Duistermaat JJ, Valkenburg HA, Meulenbelt I, Hofman A Breedveld FC, et al. Heritabilities of radiologic osteoarthritis in peripheral joints and of disc degeneration of the spine. Arthritis Rheum 1999;42:1729-35.

8 O'Reilly SC, Muir KR, Doherty M. Screening for pain in knee osteoarthritis: which question? Ann Rheum Dis 1996:55:931-3.

9 Thomas KS, Muir KR, Doherty M, Jones AC, O'Reilly SC, Bassey EJ. Home based exercise programme for knee pain and knee osteoarthritis: randomised controlled trial. BMJ 2002;325:752-5.

10 Dieppe PA. Recommended methodology for assessing the progression of osteoarthritis of the hip and knee joints. Osteoarthritis Cartilage 1995;3:73-7.

11 Laurin CA, Dussault R, Levesque HP. The tangential x-ray investigation of the patellofemoral joint: $x$-ray technique, diagnostic criteria and their interpretation. Clin Orthop Relat Res 1979;144:16-26.

12 Kellgren JH, Lawrence JS. The epidemiology of chronic rheumatism. Atlas of standard radiographs of arthritis. Vol 2. Oxford: Blackwell Scientific, 1963.

13 Nagaosa Y, Mateus M, Hassan B, Lanyon P, Doherty M. Development of a logically devised line drawing atlas for grading of knee osteoarthritis. Ann Rheum Dis 2000;59:587-95.

14 Cohen J. A coefficient of agreement for nominal scales. Educ Psychol Meas 1960;20:37-46.

15 Statistics data analysis for windows. Version 6. Texas, USA: STATA Corporation.

16 SPSS For Windows 10.1. SPSS Inc. Illinois: Chicago, 60606, USA

17 Falconer DS. Introduction to quantitative genetics, 3rd ed. Harlow: Longman Scientific and Technical, 1989.

181991 Census. County Report: Nottinghamshire (Part 1). London: HMSO, 1992.

19 Lanyon P, Muir K, Doherty S, Doherty M. Assessment of a genetic contribution to osteoarthritis of the hip: sibling study. BMJ 2000;321:1179-83.

20 Willemsen G, Vink JM, Boomsma DI. Assortative mating may explain spouses' risk of same disease. BMJ 2003;326:396.

21 Cooper C, McAlindon T, Snow S, Vines K, Young P, Kirwan J, Dieppe P. Mechanical and constitutional risk factors for symptomatic knee osteoarthritis: differences between medial tibiofemoral and patellofemoral disease. J Rheumatol 1994;21:307-13. 